\title{
Arterio-Venous (AV) Fistula: Surgical outcome in College of Medical Sciences Teaching Hospital, Bharatpur, Chitwan
}

\author{
S. Shah, ${ }^{1}$ N. Maharjan, ${ }^{2}$ D. Chapagain, ${ }^{3}$ K.G. Shrestha, ${ }^{4}$ D. J. Reddy ${ }^{5}$ \\ ${ }^{1,3,4}$ M.Ch Resident, Department of CTVS, ${ }^{2}$ Resident, Department of Surgery, ${ }^{5}$ Professor and HOD, \\ Department of CTVS,CMS-TH, Bharatpur, Nepal
}

\section{Abstract}

\section{Aims}

Arteriovenous fistula is considered as reliable form of vascular access for hemodialysis in Chronic Kidney Disease (CKD) patients. We aim to evaluate prospectively, the outcome and primary failure rate of Arteriovenous fistula in 30 Chronic kidney Disease patients with Glomerular Filtration Rate (GFR) $<30 \mathrm{ml} / \mathrm{min}$.

\section{Materials and methods}

This prospective study was conducted at the department of cardiothoracic and vascular surgery (CTVS), College of Medical Sciences, Bharatpur from May 2011 to May 2012. Thirty patients ranging from age 25 to 76 years with stage IV and V CKD, i.e. GFR below $30 \mathrm{ml} / \mathrm{min}$, were included in this study. Detailed physical examination including arterial pulses i.e. axillary, brachial, radial and ulnar and blood pressure in both upper limbs was recorded. Allens test was performed on every patient and left upper limb was used for AV fistula formation. Brachiocephalic fistula was made in 19 (63.33\%), while radiocephalic fistula was made in 11 (36.67\%) patients. Patients were evaluated post operatively, on outdoor basis, weekly for 6 weeks. All patients were evaluated for the presence or absence of complications i.e. infection, hematoma, thrombosis, aneurysms and steal syndrome.

\section{Results}

The complication was primary failure in two patients. One male patient got secondary infection and one female patient got post operative hematoma leading to $6.66 \%$ primary failure of fistula. No other complications were noted.

\section{Conclusion}

Arteriovenous fistula is the gold standard for vascular access for hemodialysis in patients with deteriorating renal function and end-stage renal disease. It is designed to improve the effectiveness of dialysis with fewer risks and complications than other vascular accesses. This study gives the higher success rate of $93.33 \%$ and concludes that age should not be a limiting factor when determining candidacy for arteriovenous fistula creation and is the safe procedure.

Key words: Arteriovenous fistula, chronic kidney disease (CKD), surgical outcome.

Correspondence: Dr. S. Shah

E-mail: santshah@hotmail.com 


\section{Introduction}

The arteriovenous fistula was first described and used as a reliable form of hemodialysis vascular access by Brescia and Cimino in $1966 .{ }^{1}$ Patients with deteriorating renal function and end-stage renal disease require vascular access that is safe, reliable, and associated with minimal complications. ${ }^{2}$ A well functioning and reliable vascular access is an absolute requirement to provide life-sustaining treatments for patients on hemodialysis. The three types of vascular access used by most dialysis patients are fistulas, grafts, and tunneled catheters. ${ }^{3}$ Autogenous arteriovenous access for hemodialysis has been shown to be superior to prosthetic graft or catheter acess in terms of patient morbidity and mortality. In addition, the maintenance of autogenous AV access is less expensive than prosthetic conduits. ${ }^{4}$ Several studies have demonstrated that autogenous arteriovenous access for chronic hemodialysis has longer patency compared with prosthetic access. ${ }^{5,6}$ The National Kidney Foundation Dialysis Outcomes Quality Initiative (NKF KDOQI) advocated the use of autogenous access if possible in all clinical scenarios. ${ }^{7}$

Present study was conducted to evaluate the outcome and primary failure rate of arteriovenous fistula, at the department of cardiothoracic and vascular surgery, collegeof medical sciences teaching hospital, Bharatpur, Chitwan.

\section{Materials and methods}

This prospective study was conducted at the Department of CTVS, College of Medical Sciences, Bharatpur from May 2011 to May 2012. Patients of age 25 to 76 years with stage IV and V CKD, i.e. GFR below $30 \mathrm{ml} / \mathrm{min}$, were included in this study. Total number of 30 patients who fulfilled the inclusion criteria were selected.

Detailed physical examination of every patient was done. Arterial pulses i.e. axillary, brachial, radial and ulnar and blood pressure in both upper limbs was recorded. Allens test was performed on every patient and left upper limb was used for AV fistula formation.

\section{Procedural detail:}

Procedure was performed using a local anesthesia i.e. $2 \%$ lignocaine injected at the site of the proposed fistula. After cleansing and sterilizing the site, a transverse curvilinear incision was given. Cephalic vein was gently mobilized to the length needed to comfortably reach the arterial anastomotic site. The upper aspect of the vein was marked during dissection while the vein was in its normal position, in order to prevent rotation. Inflation of the tourniquet cuff to 60 $\mathrm{mm} \mathrm{Hg}$ facilitated identification and dissection of the vein when necessary. Only the anterior surface of the artery was exposed. No arterial branches were ligated. A 10-mm arteriotomy was performed in the forearm while $5 \mathrm{~mm}$ in the arm with surgical blade number 11 and Pott's scissors. The vein was sharply cut, venous patency checked by injecting heparinised saline. Venous dilatation done with heparinised saline with 5 cc syringe and size of vein measured for anastomosis. An endto-side anastomosis was performed with Prolene 6/0 suture. In the forearm anastomosis was made between radial artery and cephalic vein while brachial artery and cephalic vein in the arm. Haemostasis was assessed and the wound was closed in two layers using 3/0 absorbable sutures for the subcutaneous layer and subcuticular stitch. Gentle Antiseptic dressing was done. 
S Shan et al. Arterio-Venous (AV)Fistula: Surgical Outcome in.

\section{Post-operative follow ups:}

Every patient was discharged on the 1st day after surgery on oral antibiotics and analgesic for seven days with instructions to begin hand exercises with a solid foam-rubber ball the size of a tennis ball(Fistula Ball) on the $1^{\text {st }}$ postoperative day. The follow up was performed on outpatient basis, every 7th day for 6 weeks after which fistula was released to puncture for hemodialysis. The primary failure rate was assessed in the initial 2 weeks post-operatively by feeling strong thrill at arterial anastomosis and auscultation for continuous low-pitched bruit. All patients were evaluated for the presence or absence of complications i.e. infection, hematoma, thrombosis, aneurysms and steal syndrome, on follow up visits.

\section{Result}

The total number of patients included in this study was 30 and their age ranged from 25 to 79 years with mean age of $55 \pm 20$ years (Table 1 ). Majority of the patients (50.0\%) were between 41 to 60 years of age. Out of these 30 patients, 19 (63.33\%) were male and 11 (36.67\%) were females with ratio 1.7:1. Majority of patients presented with CKD type IV and type V. Brachiocephalic fistula was made in 19(63.33\%), while radiocephalic fistula was made in 11 (36.67\%) patients (Table 2).

The complication was primary failure in two patients. One male patient got secondary infection and one female patient got post operative hematoma leading to $6.66 \%$ primary failure of fistula. No other complications were noted.

Table 1. Age distribution according to gender

\begin{tabular}{|c|c|c|c|c|c|c|}
\hline \multirow[b]{2}{*}{$\begin{array}{c}\text { Age } \\
\text { (Years) }\end{array}$} & \multicolumn{2}{|c|}{ Male } & \multicolumn{2}{|c|}{ Female } & \multicolumn{2}{|c|}{ Total } \\
\hline & $\begin{array}{c}\text { No. of } \\
\text { Patients }\end{array}$ & $\begin{array}{c}\% \\
\text { age }\end{array}$ & $\begin{array}{l}\text { No. of } \\
\text { Patient }\end{array}$ & $\begin{array}{c}\% \\
\text { age }\end{array}$ & $\begin{array}{l}\text { No. of } \\
\text { Patient }\end{array}$ & $\begin{array}{c}\% \\
\text { age }\end{array}$ \\
\hline $21-40$ & 4 & 13.33 & 1 & 3.33 & 5 & 16.67 \\
\hline $41-60$ & 9 & 30 & 6 & 20 & 15 & 50 \\
\hline Above 61 & 6 & 20 & 4 & 13.33 & 10 & 33.33 \\
\hline Total & 19 & 63.33 & 11 & 36.67 & 30 & 100 \\
\hline
\end{tabular}

Table 2. Percentage of patients according to site of AV fistula and gender

\begin{tabular}{rccccccc} 
Site & Male & \multicolumn{2}{c}{ Female } & \multicolumn{2}{c}{ Total } \\
& $\begin{array}{c}\text { No. of } \\
\text { Patients }\end{array}$ & $\begin{array}{c}\text { \% } \\
\text { age }\end{array}$ & $\begin{array}{c}\text { No. of } \\
\text { Patient }\end{array}$ & $\begin{array}{c}\text { \% } \\
\text { age }\end{array}$ & $\begin{array}{c}\text { No. of } \\
\text { Patient }\end{array}$ & $\begin{array}{c}\text { \% } \\
\text { age }\end{array}$ \\
\hline BC & 12 & 40 & 7 & 23.33 & 19 & 63.33 \\
RC & 7 & 23.33 & 4 & 13.33 & 11 & 36.67 \\
\hline Total & $\mathbf{1 9}$ & $\mathbf{6 3 . 3 3}$ & $\mathbf{1 1}$ & $\mathbf{3 6 . 6 7}$ & $\mathbf{3 0}$ & $\mathbf{1 0 0}$ \\
\hline
\end{tabular}




\section{Discussion}

Most patients with end-stage renal failure still spend an appreciable amount of time on haemodialysis (HD), either as a definitive treatment or waiting for transplants. ${ }^{8} \mathrm{HD}$ is based on diffusion - the exchange of solutes through a semipermeable membrane along a concentration gradient from one fluid (usually the plasma) to another (usually the dialysate). ${ }^{9}$ There is no consensus on the optimal timing of fistula surgery. The DOQUI guidelines recommend to establish vascular access when the serum creatinine concentration exceeds $4 \mathrm{mg} / \mathrm{dl}$ and the estimated GFR is d" $25 \mathrm{ml} /$ min. ${ }^{7}$ In our study, we have selected patients with GFR d” 30ml/min (Grade IV \& V CKD). Fistulas are usually created in the nondominant arm and may be situated on the forearm (usually a radiocephalic fistula, or socalled Brescia-Cimino fistula, in which the radial artery is anastomosed to the cephalic vein), or the elbow (usually a brachiocephalic fistula, where the brachial artery is anastomosed to the cephalic vein). ${ }^{10}$ Maturation times of 1-4 months must elapse following creation of an autologous fistula before it can be used. The fistula should, therefore, preferably be created several months in advance of the anticipated need for dialysis or an alternative temporary method of vascular access must be used while the fistula develops. ${ }^{11}$

There are three different types of vascular access: arterivenous fistula, graft and catheter but the ground breaking article by Brescia and Cimino in 1966 revolutionized the creation of the vascular access and then after the Cimino fistula was used in almost all dialysis patients. ${ }^{4,10}$ An arteriovenous fistula is preferred and has proven to be the most successful type of vascular access because it lasts longer, has low rate of complications and easy handling. ${ }^{12-14}$
In this study, we have used left upper limb and side to end anastomosis technique for arteriovenous fistula creation in all patients and made 63.33\% brachiocephalic and 36.67 radiocephalic fistulas. The presentation age in our study varied from 25 to 76 years with the mean age of $55 \pm 20$ years. Majority of the patients (50.0\%) were between 41 to 60 years of age.

The result in our study confirm that patient age is not a factor in the success of procedure and arteriovenous fistula should not be withheld from patients on the basis of age as observed by Lok et al. ${ }^{1}$ In our study, 19 (63.33\%) were male and 11 (36.67\%) were females with ratio $1.7: 1$. Out of these 30 patients, two complication of primary failure was noted. One male patient got secondary infection and one female patient got post operative hematoma leading to $6.66 \%$ primary failure of fistula. Numerous studies have reported a lower prevalence of fistula use in women than in men but the reasons for this discrepancy have not been adequately elucidated. ${ }^{15,16}$

Haimov $\mathrm{M}$ et al ${ }^{17}$ and Suwitchakul $\mathrm{C}$ et $\mathrm{al}^{18}$ reported wound infection in $4.4 \%$ and $2.0 \%$ and observed steal syndrome in $1.6 \%$ and $2.0 \%$ respectively while in our study, it was not found in any patient. Incidence of primary failure rate (within 2 weeks) in our study was 3.33\% while Rooijens PPGM et al. ${ }^{19}$ reported its incidence $15.3 \%$ and Shemesh D et al. ${ }^{20} 6.8 \%$. Early failure was reported to be $40 \%-55 \%$ in the American series and about $7 \%$ to $10 \%$ in the European series. ${ }^{15}$ So, primary failure rate was much lower in our study as compared to other ones. Thrombosis observed in different studies range from $2.0-7.0 \%{ }^{17,18}$ while in our study it was found in none. There was a hematoma 
S Shan et al. Arterio-Venous (AV)Fistula: Surgical Outcome in. formation(3.33\%) in our study while Suwitchakul C et $\mathrm{al}^{18}$ reported its incidence 3.0\%. False aneurysm was not seen in any patient in our study while in other study it was observed in $2.0 \%$ cases. ${ }^{20}$ So, in our study, overall success rate was $93.33 \%$ which is far higher in

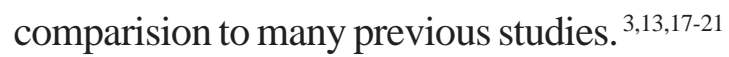

\section{Conclusion}

Arteriovenous fistula is the gold standard for vascular access for hemodialysis in patients with deteriorating renal function and end-stage renal disease. It is designed to improve the effectiveness of dialysis with fewer risks and complications than other vascular accesses. This study gives the higher success rate of $93.33 \%$ and concludes that age should not be a limiting factor when determining candidacy for arteriovenous fistula creation and is the safe procedure.

\section{References}

1. Lok CE. Fistula first initiative: advantages pitfalls. Clin J Am Soc Nephrol. 2007;2:1043-53.

2. Casey ET, Murad MH, Rizvi AZ et al. Surveillance of arteriovenous hemodialysis access: A systematic review and meta-analysis. $J$ Vasc. Surg. 2008;48:48-54.

3. Vazquez MA. Vascular access for dialysis- recent lessons and new insights. Curr. Nephrol. Hypertens. 2009:18;116-21.

4. Sidawy AN, Spergel LM Besarab A, et al. The society for vascular surgery- clinical practice guidelines for the surgical placement and maintenance fo arteriovenous hemodialysis access. J Vasc. Surg. 2008:48;2-25.

5. Huber TS, Buhler AG, Seeger JM. Evidence-based data for the hemodialysis access surgeon. Semin Dial. 2004;17:217-23.

6. Huber TS, Carter JW, Carter RL, et al. Patency of autogenous and polytetrafluoroethylene upper extremity arteriovenous hemodialysis accesses: a systematic review. J Vasc Surg. 2003;38:100511.

7. NKF-KDOQI Clinical practice guidelines and clinical practice recommendations for vascular access: update 2006. Am J Kidney Dis. 2006;48:177-247.

8. Parmar J, Aslam M, Standfield N. Pre-operative radial arterial diameter predicts early failure of arteriovenous fistula (AVF) for haemodialysis. Eur J Vasc Endovasc Surg. 2007;33:113-5.

9. Lameire N, Van Biesen W, Vanholder R. Did 20 years of technological innovations in hemodialysis contribute to better patient outcomes? Clin J Am Soc Nephrol. 2009;4:30-40.

10. Brescia MJ, Cimino JE, Appel K et al. Chronic hemodialysis using venipuncture and a surgically created arteriovenous fistula. $N$ Engl J Med. 1966;275:1089-92.

11. Zeebregts CJ, Tielliu IFJ, Hulsebos RG et al. Determinants of failure of brachiocephalic elbow fistulas for haemodialysis. Eur J Vasc Endovasc Surg. 2005;30:209-14.

12. Jennings WC, Kindred MG, Broughan TA. Creating radiocephalic arteriovenous fistulas: technical and functional success. J Am Coll Surg. 2009;208:419. 
13. Cura M, Elmerhi F, Suri R et al. Vascular malformations and arteriovenous fistulas of the kidney. Acta Radiol. 2010;51:144-9.

14. Shenoy S. Surgical anatomy of upper arm: what is needed for AVF planning. J Vasc Access. 2009;10:223-32.

15. Pisoni RL, Young EW, Dykstra DM et al. Vascular access use in Europe and the United States: results from the DOPPS. Kidney Int. 2002;61:305-16.

16. Zadeh MK, Gholipour F, Naderpour Z et al. Relationship between vessel diameter and time to maturation of arteriovenous fistula for hemodialysis access. International J of Nephrology. 2012;1-3.

17. Ferring M, Claridge M, Smith SA et al. Routine preoperative vascular ultrasound improves potency and use of arteriovenous fistulas for hemodialysis: a randomized trial. Clin J Am Soc Nephrol. 2010;5:22-36.
18. Frank T, Pedberg Jr, Keith D et al. Complications of arteriovenous hemodialysis access: recognition and management. $J$ of Vascular Surg. 2008;48:\$55-\$80.

19. Suwitchakul C. Surgical outcome of arteriovenous fistula for hemodialysis in end stage renal disease patients with diabetes mellitus. Vajira Med J. 2010;54:171-80.

20. Shemesh D, Zigelman C, Olsha O et al. Primary forearm arteriovenous fistula for hemodialysis accessan integrated approach to improve outcomes. Cardiovascular Surgery. 2003;11:35-41.

21. Tannuri U, Tannuri AC and Watanabe A. Arteriovenous fistula for chronic hemodialysis in pediatric candidates for renal transplantation: Technical details and refinements. Pediatr Transplant. 2009;13:360-4. 